\title{
Initial shifts in nitrogen impact on ecosystem carbon fluxes in an alpine meadow: patterns and causes
}

\author{
Bing Song ${ }^{1,2}$, Jian Sun ${ }^{1}$, Qingping Zhou ${ }^{3}$, Ning Zong ${ }^{1}$, Linghao $\mathbf{L i}^{2}$, and Shuli Niu ${ }^{1,4}$ \\ ${ }^{1}$ Key Laboratory of Ecosystem Network Observation and Modeling, Institute of Geographic Sciences and Natural Resources \\ Research, Chinese Academy of Sciences, Datun Road, Beijing 100101, China \\ ${ }^{2}$ State Key Laboratory of Vegetation and Environmental Change, Institute of Botany, Chinese Academy of Sciences, \\ Xiangshan, Beijing 100093, China \\ ${ }^{3}$ Institute of Qinghai-Tibetan Plateau, Southwest Minzu University, Chengdu 610041, China \\ ${ }^{4}$ Department of Resources and Environment, University of Chinese Academy of Sciences, Beijing 100049, China \\ Correspondence to: Shuli Niu (sniu@igsnrr.ac.cn)
}

Received: 14 October 2016 - Discussion started: 10 November 2016

Revised: 2 August 2017 - Accepted: 4 August 2017 - Published: 13 September 2017

\begin{abstract}
Increases in nitrogen (N) deposition can greatly stimulate ecosystem net carbon (C) sequestration through positive $\mathrm{N}$-induced effects on plant productivity. However, how net ecosystem $\mathrm{CO}_{2}$ exchange (NEE) and its components respond to different $\mathrm{N}$ addition rates remains unclear. Using an $\mathrm{N}$ addition gradient experiment (six levels: 0 , $2,4,8,16,32 \mathrm{gN} \mathrm{m}^{-2} \mathrm{yr}^{-1}$ ) in an alpine meadow on the Qinghai-Tibetan Plateau, we explored the responses of different ecosystem $\mathrm{C}$ fluxes to an $\mathrm{N}$ addition gradient and revealed mechanisms underlying the dynamic responses. Results showed that NEE, ecosystem respiration (ER), and gross ecosystem production (GEP) all increased linearly with $\mathrm{N}$ addition rates in the first year of treatment but shifted to $\mathrm{N}$ saturation responses in the second year with the highest NEE $\left(-7.77 \pm 0.48 \mu \mathrm{mol} \mathrm{m}^{-2} \mathrm{~s}^{-1}\right)$ occurring under an $\mathrm{N}$ addition rate of $8 \mathrm{gN} \mathrm{m}^{-2} \mathrm{yr}^{-1}$. The saturation responses of $\mathrm{NEE}$ and GEP were caused by $\mathrm{N}$-induced accumulation of standing litter, which limited light availability for plant growth under high $\mathrm{N}$ addition. The saturation response of ER was mainly due to an $\mathrm{N}$-induced saturation response of aboveground plant respiration and decreasing soil microbial respiration along the $\mathrm{N}$ addition gradient, while decreases in soil microbial respiration under high $\mathrm{N}$ addition were caused by $\mathrm{N}$-induced reductions in soil $\mathrm{pH}$. We also found that various components of ER, including aboveground plant respiration, soil respiration, root respiration, and microbial respiration, responded differentially to the $\mathrm{N}$ addition gradient. These results reveal temporal dynamics of $\mathrm{N}$ impacts and the rapid
\end{abstract}

shift in ecosystem $\mathrm{C}$ fluxes from $\mathrm{N}$ limitation to $\mathrm{N}$ saturation. Our findings bring evidence of short-term initial shifts in responses of ecosystem $\mathrm{C}$ fluxes to increases in $\mathrm{N}$ deposition, which should be considered when predicting long-term changes in ecosystem net $\mathrm{C}$ sequestration.

\section{Introduction}

Anthropogenic reactive nitrogen $(\mathrm{N})$ inputs to the terrestrial biosphere has increased more than 3-fold over the past century and is predicted to increase further (Lamarque et al., 2005; Galloway et al., 2008). Because of the strong coupling of ecosystem carbon $(\mathrm{C})$ and $\mathrm{N}$ cycles, excess $\mathrm{N}$ deposition could have significant impacts on the ecosystem $\mathrm{C}$ cycle (LeBauer and Treseder, 2008; Liu and Greaver, 2010; Lu et al., 2011). Ecosystem net $\mathrm{C}$ sequestration is predicted to increase or have no significant change under rising $\mathrm{N}$ deposition (Nadelhoffer et al., 1999; Magnani et al., 2007; Reay et al., 2008; Niu et al., 2010; Lu et al., 2011; FernandezMartinez et al., 2014). However, we have a limited understanding of the dynamic $\mathrm{N}$ responses of $\mathrm{C}$ sequestration in terrestrial ecosystems, which is crucial for model projection of the future terrestrial $\mathrm{C}$ cycle under rising $\mathrm{N}$ deposition (Reay et al., 2008).

Although $\mathrm{N}$ addition generally enhances plant growth and ecosystem net primary productivity (NPP) based on global syntheses of $\mathrm{N}$ addition experiments (LeBauer and Treseder, 
2008; Xia and Wan, 2008; Lu et al., 2011), the responses of ecosystem $\mathrm{C}$ fluxes vary with $\mathrm{N}$ loading rates (Liu and Greaver, 2010; Lu et al., 2011). According to the N saturation hypothesis, NPP is assumed to slowly increase with N addition rates first, then reach its maximum value at the $\mathrm{N}$ saturation point, and finally decline with further increase in $\mathrm{N}$ input (Aber et al., 1989; Lovett and Goodale, 2011). During this process, NPP shifts from an N-limited, an $\mathrm{N}$ intermediate, to an $\mathrm{N}$ saturation stage as $\mathrm{N}$ deposition increases. Similarly, net ecosystem $\mathrm{CO}_{2}$ exchange (NEE) and its components of gross ecosystem production (GEP) and ecosystem respiration (ER) may also respond nonlinearly to increasing $\mathrm{N}$ loading rates (Fleischer et al., 2013; Gomez-Casanovas et al., 2016; Tian et al., 2016). In the N-limited stage, low rates of $\mathrm{N}$ addition could stimulate ecosystem productivity (Aber et al., 1989), GEP (Fleischer et al., 2013; Gomez-Casanovas et al., 2016), and ER (Hasselquist et al., 2012; Zhu et al., 2016), while in the $\mathrm{N}$ saturation stage, high doses of $\mathrm{N}$ addition could have negative effects on GEP and ER (Treseder, 2008; Janssens et al., 2010; Maaroufi et al., 2015). The unbalanced responses of GEP and ER may lead to changes in NEE.

Moreover, ER can be divided into aboveground plant respiration, belowground plant respiration (root respiration), and soil microbial respiration. These components of ER could be affected by plant aboveground biomass, root biomass, soil organic matter, and microbial biomass $\mathrm{C}$, which may respond variously to $\mathrm{N}$ addition (Phillips and Fahey, 2007; Hasselquist et al., 2012). For example, root respiration would be enhanced or not significantly changed under $\mathrm{N}$ addition, while soil microbial respiration may be suppressed by $\mathrm{N}$ addition (Zhou et al., 2014). The different responses of various components of ER to $\mathrm{N}$ addition will also consequently change the response of NEE. Nevertheless, there is limited knowledge on how various components of NEE respond differentially to $\mathrm{N}$ addition gradient. In addition, the $\mathrm{N}$ responses of ecosystem $\mathrm{C}$ fluxes may shift over time because of changes in plant community structure and other limiting factors (Niu et al., 2010). It is not clear when and how ecosystem $\mathrm{C}$ fluxes get $\mathrm{N}$ saturated under increasing $\mathrm{N}$ input. The mechanisms underlying the saturation response of $\mathrm{C}$ fluxes are even far from clear, which prevent us from accurately predicting the $\mathrm{C}$ cycle in response to rising $\mathrm{N}$ deposition.

In this study, we explored the responses of various ecosystem $\mathrm{C}$ cycle processes to an $\mathrm{N}$ addition gradient in an alpine meadow on the Qinghai-Tibetan Plateau. The QinghaiTibetan Plateau has an area of 2.5 million $\mathrm{km}^{2}$ with alpine meadow covering $35 \%$ of this area, and it is sensitive to environmental change and human activities (Chen et al., 2013). The objectives of this study were to explore how different components of ecosystem $\mathrm{C}$ fluxes respond to increasing $\mathrm{N}$ loading gradient. Specifically, we addressed the following questions. (i) How do NEE and its components respond to the $\mathrm{N}$ addition gradient in the alpine meadow? (ii) Can various $\mathrm{C}$ cycle processes get $\mathrm{N}$ saturated? If so, at which $\mathrm{N}$ addition level are they saturated and how do the responses shift with time? (iii) What are the mechanisms underlying $\mathrm{N}$ saturation responses of different $\mathrm{C}$ cycle processes?

\section{Materials and methods}

\subsection{Study site}

The study site is located in an alpine meadow in Hongyuan County, Sichuan Province, China, which is on the eastern Qinghai-Tibetan Plateau $\left(32^{\circ} 48^{\prime} \mathrm{N}, 102^{\circ} 33^{\prime} \mathrm{E}\right)$. The altitude is $\sim 3500 \mathrm{~m}$. Long-term (1961-2013) mean annual precipitation is $747 \mathrm{~mm}$ with approximately $80 \%$ occurring in May to September. Long-term mean annual temperature is $1.5^{\circ} \mathrm{C}$ with monthly mean temperature ranging from $-9.7^{\circ} \mathrm{C}$ in January to $11.1^{\circ} \mathrm{C}$ in July. The dominant species in this alpine meadow are Deschampsia caespitosa (Linn.) Beauv., Kobresia setchwanensis Hand.-Mazz., Carex schneideri Nelmes, and Anemone rivularis Buch.-Ham. The vegetation cover of this grassland is over $90 \%$. The soil in the study site is classified as Mat Cry-gelic Cambisol according to the Chinese classification, with surface soil bulk density being $0.89 \mathrm{~g} \mathrm{~cm}^{-3}$. The soil organic $\mathrm{C}$ content and total $\mathrm{N}$ content are $37 \mathrm{gC} \mathrm{kg}^{-1}$ and $3.5 \mathrm{gN} \mathrm{kg}^{-1}$, respectively. The background $\mathrm{N}$ deposition ranges from 0.87 to $1.38 \mathrm{gN} \mathrm{m}^{-2} \mathrm{yr}^{-1}$ on the eastern Qinghai-Tibetan Plateau, and the natural $\mathrm{N}$ deposition rate in China ranges from 0.11 to $6.35 \mathrm{gN} \mathrm{m}^{-2} \mathrm{yr}^{-1}$ (Lü and Tian, 2007).

\subsection{Experimental design}

We conducted an $\mathrm{N}$ addition experiment with six levels of $\mathrm{N}$ addition rate $\left(0,2,4,8,16,32 \mathrm{gN} \mathrm{m}^{-2} \mathrm{yr}^{-1}\right)$ in early 2014 . The six $\mathrm{N}$ treatments were represented by N0 (control), N2, $\mathrm{N} 4, \mathrm{~N} 8, \mathrm{~N} 16$, and N32. The treatments were randomly assigned with five replications, so there were totally 30 plots. Each plot was $8 \times 8 \mathrm{~m}$, and the distance between any two adjacent plots was $3 \mathrm{~m}$. The $\mathrm{N}$ addition treatments started from May 2014. In 2014 and 2015, N was applied by hand as $\mathrm{NH}_{4} \mathrm{NO}_{3}(>99 \%)$ every month from May to September (i.e., during the growing season) before rainfall. The $\mathrm{N}$ amount was same in each month. In order to distribute dry $\mathrm{NH}_{4} \mathrm{NO}_{3}$ evenly in the plots, we mixed dry $\mathrm{NH}_{4} \mathrm{NO}_{3}$ with enough amounts of soil to apply.

\subsection{Ecosystem $\mathrm{C}$ cycle properties and soil $\mathrm{pH}$ measurement}

Ecosystem $\mathrm{C}$ fluxes were measured using a transparent static chamber $(0.5 \times 0.5 \times 0.5 \mathrm{~m})$ attached to an infrared gas analyzer (LI-6400XT; LI-COR Environmental, Lincoln, Nebraska, USA) in the field. During each measurement, the chamber was positioned over a square steel frame, which was permanently inserted into soil and offered a flat base for the chamber. Inside the chamber, two electric fans were 
mounted in order to mix the chamber atmosphere. The measurements were conducted twice per month on clear, sunny days from May to September in 2014 and 2015. Nine consecutive recordings of $\mathrm{CO}_{2}$ concentration were taken at each base at $10 \mathrm{~s}$ intervals. $\mathrm{CO}_{2}$ flux rates were determined from the time courses of the concentrations to calculate NEE. After the measurement of NEE, the chamber was covered by an opaque cloth and the $\mathrm{CO}_{2}$ measurement was repeated. As the second measurement eliminated light, the $\mathrm{CO}_{2}$ flux value obtained represented ER. GEP was calculated as the difference between NEE and ER. Negative or positive NEE and GEP values represent net $\mathrm{C}$ uptake or release, respectively. The detailed methods have also been described in Niu et al. (2008, 2013).

Soil respiration (SR) was assessed following the measurement of NEE and ER. It was also measured with LI6400XT attaching a soil $\mathrm{CO}_{2}$ flux chamber $\left(991 \mathrm{~cm}^{3}\right.$ in total volume; LI-6400-09; LI-COR Environmental, Lincoln, Nebraska, USA). A PVC collar $(10.5 \mathrm{~cm}$ in diameter and $5 \mathrm{~cm}$ in height) was permanently installed $2-3 \mathrm{~cm}$ into the soil. The soil respiration chamber attached to LI-6400XT was placed on each PVC collar for 1-2 min to measure SR. Living plants inside the collars were removed regularly by hand to eliminate aboveground plant respiration. Soil heterotrophic respiration (i.e., soil microbial respiration, $R_{\text {mic }}$ ) was measured using the same method as soil respiration. Differently, the PVC collar was $40 \mathrm{~cm}$ in height and installed $36-38 \mathrm{~cm}$ into the soil. As $>90 \%$ of plant roots were distributed in the topsoil $(0-20 \mathrm{~cm}), 40 \mathrm{~cm}$ long PVC collars could cut off old plant roots and prevented new roots from growing inside the collars. Plants in the collars were completely removed by hand to exclude $\mathrm{C}$ supply. The experiment was conducted in early 2014 and the measurements of $\mathrm{CO}_{2}$ fluxes above these $40 \mathrm{~cm}$ long PVC collars began in late July 2014, leaving enough time for the remaining plant roots inside the collars to die. Thus $\mathrm{CO}_{2}$ fluxes in those deep collars represented $R_{\text {mic }}$. The method was the same as in Wan et al. (2005) and Zhou et al. (2007). Root respiration $\left(R_{\text {root }}\right)$ was calculated by the value of SR minus $R_{\text {mic }}$. Aboveground plant respiration $\left(R_{\text {above }}\right)$ was calculated by ER minus SR, and ecosystem plant respiration $\left(R_{\text {plant }}\right)$ was calculated as the difference between ER and $R_{\text {mic }}$. All the measurements of ecosystem C fluxes were simultaneous.

Soil samples were collected from the topsoil $(0-10 \mathrm{~cm})$ of the 30 plots on 15 August 2014 and 14 August 2015. Two soil cores $(8 \mathrm{~cm}$ in diameter and $10 \mathrm{~cm}$ in depth) were taken at least $1 \mathrm{~m}$ from the edge in each plot, and then completely mixed to get a composite sample. The soil samples were sieved by a $2 \mathrm{~mm}$ mesh and then were air-dried for chemical analysis. Soil $\mathrm{pH}$ was determined with a glass electrode in a $1: 2.5$ soil / water solution $(w / v)$.

\subsection{Statistical analysis}

Repeated-measures ANOVA was used to examine $\mathrm{N}$ addition effects on each ecosystem $\mathrm{C}$ flux over the growing season in 2014 and 2015. When we evaluate $\mathrm{N}$ addition effects on the different components of ER and their proportions, we averaged their values across the year and then used one-way ANOVA to test the differences among treatments. To test the response pattern of ecosystem $\mathrm{C}$ cycle properties to the $\mathrm{N}$ addition gradient, we fitted the response parameter to linear or quadratic functions which had higher $R^{2}$. We also compared the Akaike information criterion (AIC) between the functions. Simple linear regression analyses were used to evaluate relationships of ER with its components and NEE across the 2 years. $R_{\text {mic }}$ and $\mathrm{pH}$ were calculated by data in different $\mathrm{N}$ addition treatments minus data in the control treatment. Stepwise multiple linear regressions were used to test the drivers which best predict $R_{\text {mic }}$. All data were tested for normal distribution before statistical analysis. The a posteriori comparisons were performed by Duncan test, and the effects were considered to be significantly different if $P<0.05$. All statistical analyses were conducted with SAS V.8.1 software (SAS Institute Inc., Cary, North Carolina, USA).

\section{Results}

\subsection{NEE and its components in response to the $\mathrm{N}$ addition gradient}

NEE varied throughout the growing seasons in both 2014 and 2015. The maximum rates of net $\mathrm{CO}_{2}$ uptake (indicated by large negative values of NEE) occurred in July in both years (Fig. 1a, d). $\mathrm{N}$ addition had a significant impact on NEE in $2014(P=0.020)$ and a marginally significant effect in 2015 $(P=0.059)$ (Table 1). Mean NEE across months had different responses to the $\mathrm{N}$ addition gradient between the 2 years (Fig. 1a, d). It increased linearly with $\mathrm{N}$ addition rates in 2014 (Table 2; Fig. 2a) but shifted to a saturating response with $\mathrm{N}$ addition rates in 2015 (Table 2; Fig. 2d). The largest NEE was $-7.77 \pm 0.48 \mu \mathrm{mol} \mathrm{m}^{-2} \mathrm{~s}^{-1}$ under an $8 \mathrm{gN} \mathrm{m}^{-2} \mathrm{yr}^{-1}$ addition rate (N8) in 2015.

The $\mathrm{N}$ addition gradient had significant effects on ER $(P=0.033$ and 0.006 , respectively) and GEP $(P=0.002$ and 0.038 , respectively) in both 2014 and 2015 (Table 1). Similar to NEE, both ER and GEP showed linear responses to $\mathrm{N}$ addition rates in 2014 but shifted to saturation responses in 2015 (Table 2; Fig. 2). On average, ER was enhanced by $0.9-16.1 \%$ in 2014 and $7.9-23.7 \%$ in 2015 under different $\mathrm{N}$ addition treatments. GEP was increased by $2.4-19.2 \%$ in 2014 and $6.7-20.5 \%$ in 2015 under different $\mathrm{N}$ addition levels, with maximal values being $-24.40 \pm 0.48 \mathrm{mmol} \mathrm{m}^{-2} \mathrm{~s}^{-1}$ under $32 \mathrm{gN} \mathrm{m}^{-2} \mathrm{yr}^{-1}$ in 2014 and $-15.38 \pm 0.72 \mu \mathrm{mol} \mathrm{m}^{-2} \mathrm{~s}^{-1}$ under $16 \mathrm{gN} \mathrm{m}^{-2} \mathrm{yr}^{-1}$ in 2015 (Fig. 2). 

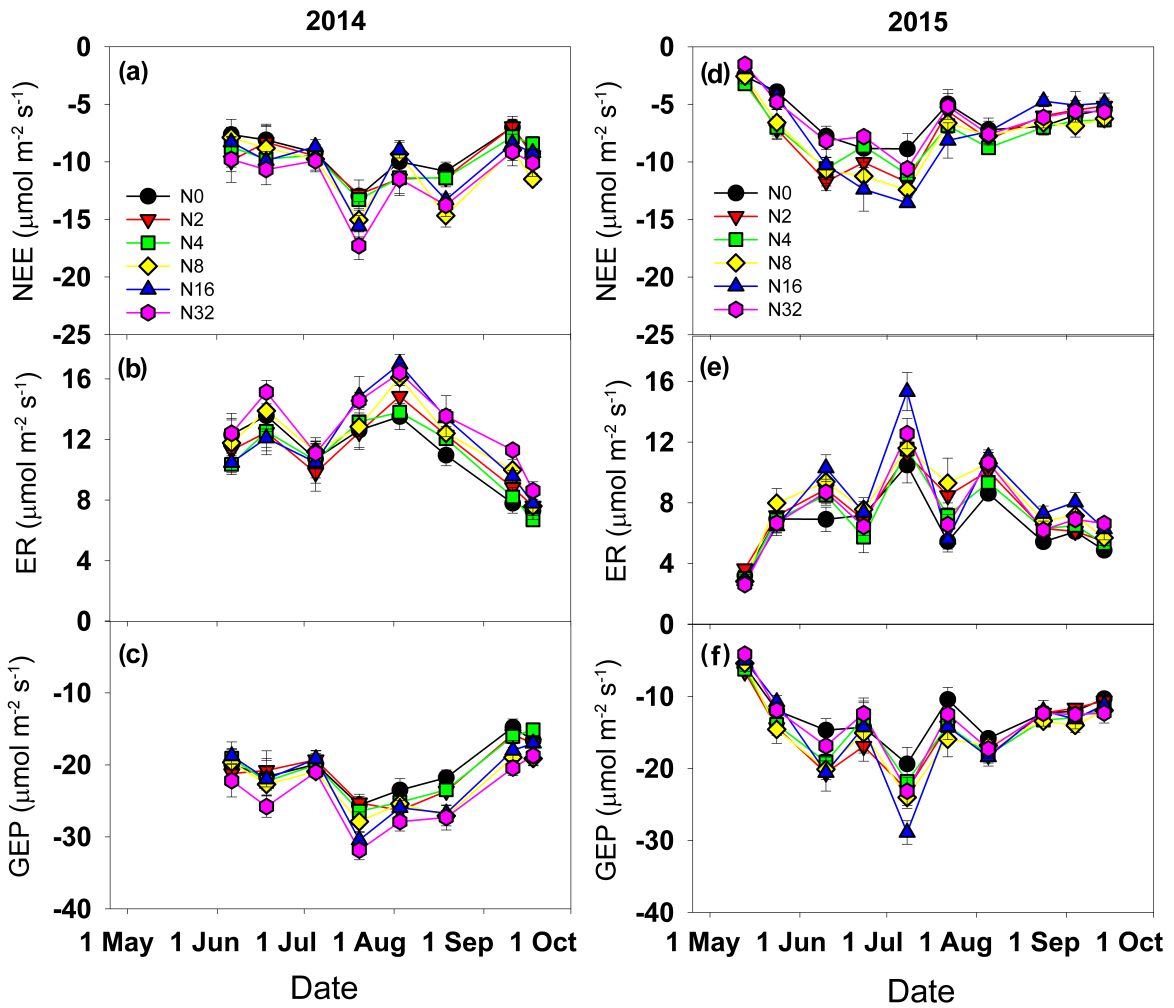

Figure 1. Seasonal dynamics of net ecosystem $\mathrm{CO}_{2}$ exchange (NEE) (a, d), ecosystem respiration (ER) (b, e), and gross ecosystem production (GEP) (c, f) in 2014 and 2015. N0, N2, N4, N8, N16, and N32 represent N addition rates of 0, 2, 4, 8, 16, and 32 gN m ${ }^{-2} \mathrm{yr}^{-1}$, respectively.

Table 1. Results ( $F$ and $P$ values) of one-way ANOVA on the effects of nitrogen addition on ecosystem C fluxes in 2014 and 2015 . NEE: net ecosystem $\mathrm{CO}_{2}$ exchange; ER: ecosystem respiration; GEP: gross ecosystem production; SR: soil respiration; $R_{\text {mic }}$ : soil microbial respiration; $R_{\text {plant }}$ : plant respiration; $R_{\text {above }}$ : aboveground plant respiration; $R_{\text {root }}$ : plant root respiration.

\begin{tabular}{cccc|cc|c|c|c|c|c|c}
\hline & & \multicolumn{2}{c}{ NEE } & \multicolumn{2}{c|}{ ER } & \multicolumn{2}{c|}{ GEP } & \multicolumn{2}{c|}{ SR } & \multicolumn{2}{c}{$R_{\text {mic }}$} \\
\cline { 2 - 11 } & $\mathrm{d} f$ & $F$ & $P$ & $F$ & $P$ & $F$ & $P$ & $F$ & $P$ & $F$ & $P$ \\
\hline 2014 & 5 & 3.35 & 0.020 & 2.95 & 0.033 & 5.37 & 0.002 & 1.56 & 0.209 & 1.49 & 0.246 \\
2015 & 5 & 2.50 & 0.059 & 4.35 & 0.006 & 2.83 & 0.038 & 3.94 & 0.010 & 1.40 & 0.259 \\
\hline
\end{tabular}

\begin{tabular}{|c|c|c|c|c|c|c|c|c|c|c|c|c|c|}
\hline & \multirow[b]{2}{*}{$\mathrm{d} f$} & \multicolumn{2}{|c|}{$R_{\text {plant }}$} & \multicolumn{2}{|c|}{$R_{\text {above }}$} & \multicolumn{2}{|c|}{$R_{\text {root }}$} & \multicolumn{2}{|c|}{$R_{\text {above }} / \mathrm{ER}$} & \multicolumn{2}{|c|}{$R_{\text {root }} / \mathrm{ER}$} & \multicolumn{2}{|c|}{$R_{\mathrm{mic}} / \mathrm{ER}$} \\
\hline & & $F$ & $P$ & $F$ & $P$ & $F$ & $P$ & $F$ & $F$ & $F$ & $P$ & $F$ & $P$ \\
\hline 2014 & 5 & 1.06 & 0.409 & 3.84 & 0.011 & 2.64 & 0.049 & 3.08 & 0.027 & 3.56 & 0.015 & 0.28 & 0.919 \\
\hline 2015 & 5 & 3.25 & 0.022 & 5.38 & 0.002 & 0.78 & 0.573 & 5.54 & 0.002 & 0.97 & 0.456 & 2.46 & 0.062 \\
\hline
\end{tabular}

\subsection{Components of ecosystem respiration in response to the $\mathbf{N}$ addition gradient}

We divided ER into $R_{\text {above }}, \mathrm{SR}, R_{\text {root }}$, and $R_{\text {mic }}$, and found that different ER components showed diverse responses to the $\mathrm{N}$ addition gradient. Mean SR across months was not significantly changed by the $\mathrm{N}$ addition gradient in 2014 (Table 1; Fig. 3). However, in 2015, it ranged from $4.98 \pm 0.33$ to $6.23 \pm 0.23 \mu \mathrm{mol} \mathrm{m}^{-2} \mathrm{~s}^{-1}$ under different $\mathrm{N}$ addition lev- els, with a significant reduction under high $\mathrm{N}$ addition levels of 16 and $32 \mathrm{gN} \mathrm{m}^{-2} \mathrm{yr}^{-1}(P=0.010$; Fig. 3). Additionally, the relationship between $\mathrm{SR}$ and $\mathrm{N}$ addition rates was not significant in 2014 (Fig. 3a), while SR leveled off under high $\mathrm{N}$ addition rates in 2015 (Fig. 3c). Interestingly, $R_{\text {mic }}$ increased linearly with $\mathrm{N}$ addition rates in 2014 (Table 2; Fig. 3b), while it decreased with $\mathrm{N}$ addition rates in 2015 (Table 2; Fig. 3d). Comparing among various components of $\mathrm{ER}$, only $R_{\text {mic }}$ showed distinctively inverse responses to $\mathrm{N}$ 
Table 2. Comparisons of the Akaike information criterion (AIC) among functions describing the relationships between NEE, ER, GEP, SR, and $R_{\text {mic }}(Y)$ and N addition rates $(X)$. Quadratic functions work better than linear ones for ecosystem C fluxes in 2015. NEE: net ecosystem $\mathrm{CO}_{2}$ exchange; ER: ecosystem respiration; GEP: gross ecosystem production; SR: soil respiration; $R_{\text {mic }}$ : soil microbial respiration.

\begin{tabular}{lrr|rr}
\hline & \multicolumn{2}{c|}{ Functions in 2014 } & \multicolumn{2}{c}{ Functions in 2015 } \\
\cline { 2 - 5 } & Linear & Quadratic & Linear & Quadratic \\
& & & \\
NEE & 78.39 & 80.26 & 88.69 & 84.82 \\
ER & 71.68 & 73.48 & 90.12 & 82.30 \\
GEP & 77.96 & 79.86 & 87.69 & 77.68 \\
SR & 87.88 & 87.34 & 79.43 & 78.18 \\
$R_{\text {mic }}$ & 78.33 & 80.27 & 85.15 & 84.48 \\
\hline
\end{tabular}

${ }^{1}$ Linear model: $Y=b_{1}+b_{2} \times X .{ }^{2}$ Quadratic model:

$Y=b_{1}+b_{2} \times X+b_{3} \times X^{2}$.

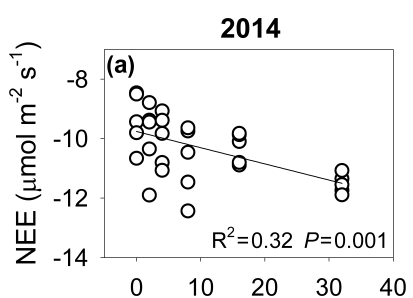

$\mathrm{N}$ addition rate $\left(\mathrm{g} \mathrm{m}^{-2} \mathrm{yr}^{-1}\right)$

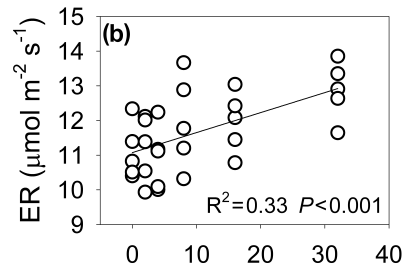

$\mathrm{N}$ addition rate $\left(\mathrm{g} \mathrm{m}^{-2} \mathrm{yr}^{-1}\right)$
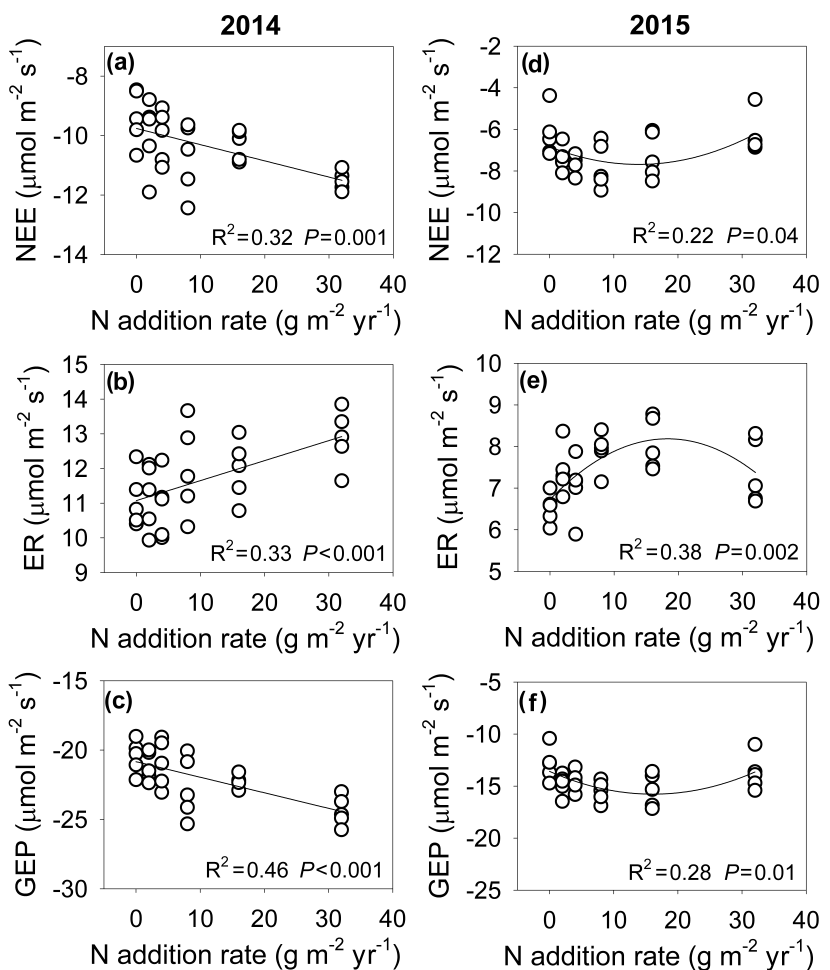

$\mathrm{N}$ addition rate $\left(\mathrm{g} \mathrm{m}^{-2} \mathrm{yr}^{-1}\right)$

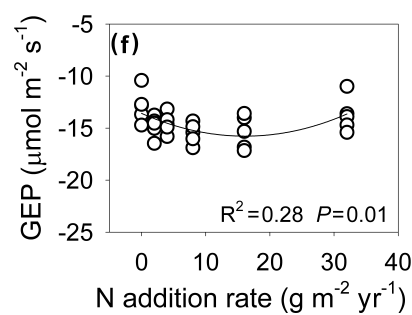

Figure 2. Relationships between $\mathrm{N}$ addition rate and net ecosystem $\mathrm{CO}_{2}$ exchange (NEE) (a, d), ecosystem respiration (ER) $(\mathbf{b}, \mathbf{e})$, and gross ecosystem production (GEP) (c, f) in 2014 and 2015.

addition rates between the years. $R_{\text {above }}$ increased with increasing $\mathrm{N}$ addition rates in 2014 (Fig. 4b) but reached its maximum value at N16 in 2015 (Fig. 4e). By contrast, $R_{\text {root }}$ decreased with increasing $\mathrm{N}$ addition rates in 2014 (Fig. 4c), while it had no statistically significant response to the $\mathrm{N}$ addition gradient in 2015 (Fig. 4f).

In addition, the proportions of different efflux components to ER differed in response to the $\mathrm{N}$ addition gradient between years (Fig. 5). The proportions of $R_{\text {above }}$ to ER kept increasing with $\mathrm{N}$ addition rates in 2014 but became saturated at

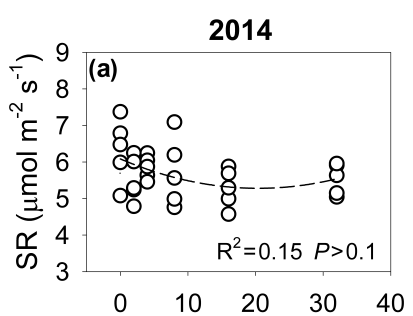

$\mathrm{N}$ addition rate $\left(\mathrm{g} \mathrm{m}^{-2} \mathrm{yr}^{-1}\right)$
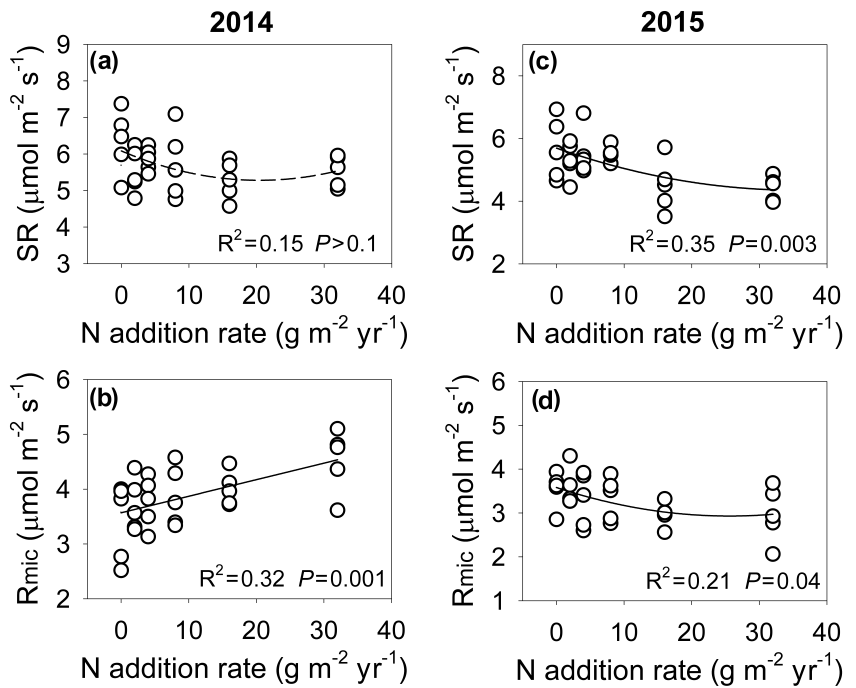

Figure 3. Relationships between $\mathrm{N}$ addition rate and soil respiration $(\mathrm{SR})(\mathbf{a}, \mathbf{c})$ and soil microbial respiration $\left(R_{\text {mic }}\right)(\mathbf{b}, \mathbf{d})$ in 2014 and 2015.

N16 in 2015 (Fig. 5a, d). The proportions of $R_{\text {root }}$ to ER ranged from $31.90 \pm 6.69 \%$ in N0 plots to $11.18 \pm 1.28 \%$ in N32 plots in 2014 (Fig. 5b), but they were not significantly different among $\mathrm{N}$ addition levels in 2015 (Table 1; Fig. 5e). In 2014, the contributions of $R_{\text {mic }}$ to ER did not significantly change under $\mathrm{N}$ addition treatments (Table 1; Fig. 5c), whereas they declined along the $\mathrm{N}$ addition gradient in 2015 (Fig. 5f).

\subsection{Causes of the $\mathbf{N}$ saturation responses of ecosystem C fluxes}

In order to examine the causes of the $\mathrm{N}$ saturation responses of NEE and ER in 2015, we examined the relationship between ER and its various components and also NEE. The results showed that ER had a significantly positive correlation with $R_{\text {above }}$ (Fig. 6a) but not with $R_{\text {root }}$ (Fig. 6b) and had a significantly negative correlation with $R_{\text {mic }}$ (Fig. 6c). 

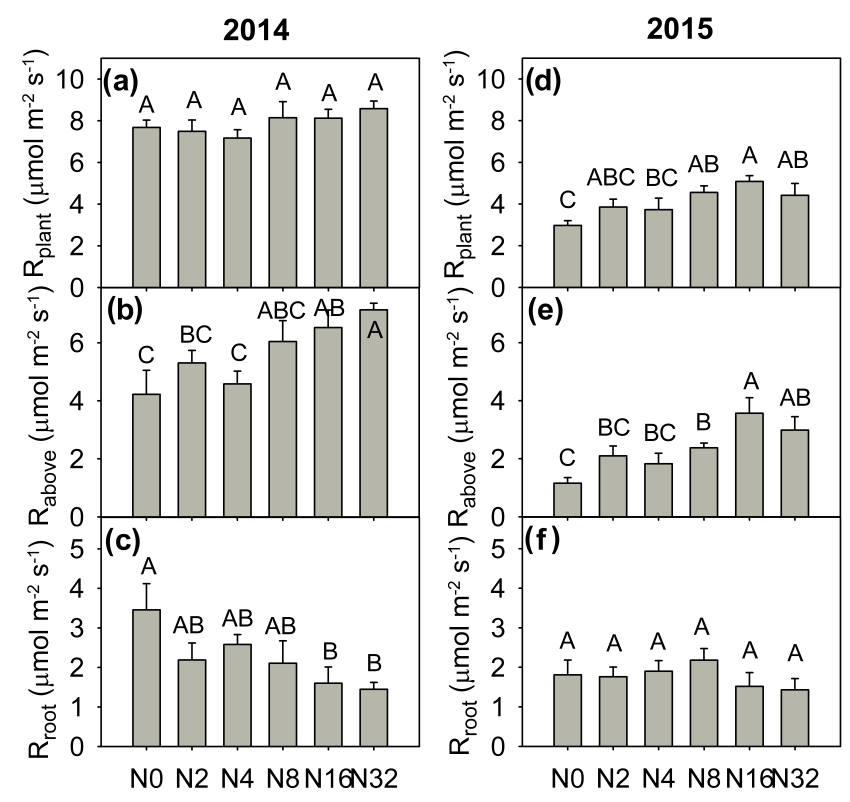

Figure 4. Plant respiration and its components in response to the $\mathrm{N}$ addition gradient in 2014 and 2015 (mean \pm SE, $n=5$ ). $R_{\text {plant }}$ : plant respiration $(\mathbf{a}, \mathbf{d}) ; R_{\text {above }}$ : aboveground plant respiration $(\mathbf{b}$, e); $R_{\text {root }}$ : plant root respiration (c, f). N0, N2, N4, N8, N16, and N32 represent $\mathrm{N}$ addition rates of $0,2,4,8,16$, and $32 \mathrm{gN} \mathrm{m}^{-2}, \mathrm{yr}^{-1}$, respectively.

Moreover, NEE closely correlated with ER (Fig. 6d). Using stepwise multiple linear regressions, we further explored the causes of decreasing $R_{\text {mic }}$ with $\mathrm{N}$ addition in 2015 and examined the relationships of the $\mathrm{N}$-induced reduction in $R_{\text {mic }}$ and $\mathrm{N}$-induced reductions in soil $\mathrm{pH}(\mathrm{pH})$ and soil $\mathrm{N}$ availability $\left(\mathrm{NH}_{4}^{+}-\mathrm{N}, \mathrm{NO}_{3}^{-}-\mathrm{N}\right)$. The result showed that $\mathrm{pH}$ was the best factor to predict $R_{\text {mic }}$. N addition significantly reduced soil pH in 2015 (Fig. 7a), and $R_{\text {mic }}$ was positively dependent on pH in 2015 (Fig. 7b) but not in 2014.

\section{Discussion}

\subsection{Nitrogen saturation responses of ecosystem C fluxes and the causes}

Our results showed that initial ecosystem C fluxes (NEE, ER, and GEP) in 2014 suggested ecosystem $N$ limitation, whereas in 2015 these $\mathrm{C}$ fluxes clearly suggested N saturation under high $\mathrm{N}$ addition rates. These findings not only extend the $\mathrm{N}$ saturation hypothesis for the response of NPP to N addition (Aber et al., 1998, 1989; Lovett and Goodale, 2011) but also provide comprehensive evidence of potential relationships between various ecosystem C fluxes and ecosystem $\mathrm{N}$ dynamics. Previous $\mathrm{N}$ addition studies used only one level of $\mathrm{N}$ addition and found that NEE showed a positive (Niu et al., 2010; Huff et al., 2015) or no significant response (Harpole et al., 2007; Bubier et al., 2007) to $\mathrm{N}$ addition. Using
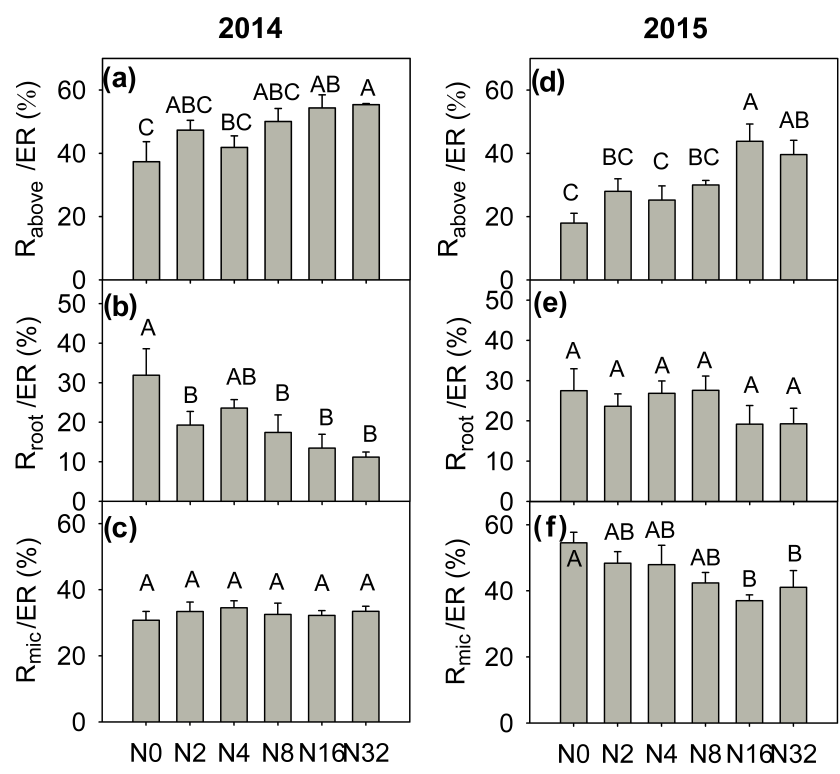

Figure 5. The contributions of different source components to ecosystem respiration (ER) in response to the $\mathrm{N}$ addition gradient in 2014 and 2015 (mean $\pm \mathrm{SE}, n=5$ ). $R_{\text {above }}$ : aboveground plant respiration; $R_{\text {root }}$ : plant root respiration; $R_{\text {mic }}$ : soil microbial respiration. $\mathrm{N} 0, \mathrm{~N} 2, \mathrm{~N} 4, \mathrm{~N} 8, \mathrm{~N} 16$, and $\mathrm{N} 32$ represent $\mathrm{N}$ addition rate of $0,2,4,8,16$, and $32 \mathrm{gN} \mathrm{m}^{-2} \mathrm{yr}^{-1}$, respectively.

one level of $\mathrm{N}$ addition only might not be enough to capture or quantify complex ecosystem responses to $\mathrm{N}$ addition. By using an $\mathrm{N}$ addition gradient experiment, this study comprehensively showed the saturation responses of NEE and its components to different $\mathrm{N}$ loading rates.

The $\mathrm{N}$ saturation response of NEE in 2015 was mainly attributed to the saturation responses of ER and GEP (Fig. 2), while the $\mathrm{N}$ saturation response of ER was likely caused by the saturation response of aboveground plant respiration and decreasing soil microbial respiration along the $\mathrm{N}$ addition gradient. The decrease in aboveground plant respiration under N32 treatment was primarily due to $\mathrm{N}$ addition stimulating plant growth and thus standing litter accumulation after plant senescence (Supplement Figs. S1-S2). In 2014, plant aboveground biomass (AGB) was stimulated under the high $\mathrm{N}$ addition treatment, especially AGB of grasses (Fig. S2). In this grassland, grasses usually have higher height than other plants. The accumulation of grasses' standing litter under the N32 treatment limited light conditions for other plants and negatively influenced plant growth in the early growing season in 2015. Therefore, GEP and NEE did not keep increasing at the highest $\mathrm{N}$ addition rate, leading to $\mathrm{N}$ saturation response. The $\mathrm{N}$-induced light limitation for plant growth was also observed in other ecosystems, like temperate grassland (Niu et al., 2010; Kim and Henry, 2013). Moreover, our results showed that most components of ER had a similar response patterns between the 2 years except for soil microbial respiration, which increased in 2014 but decreased in 2015 

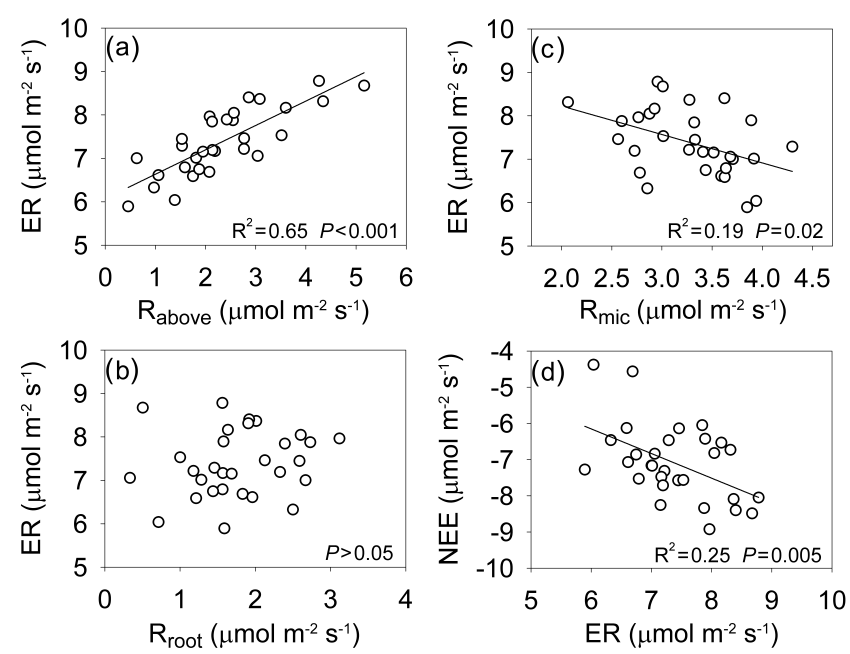

Figure 6. Relationships between aboveground plant respiration ( $\left.R_{\text {above }}\right)$, root respiration $\left(R_{\text {root }}\right)$, soil microbial respiration $\left(R_{\text {mic }}\right)$ and ecosystem respiration (ER) (a, b, c), ER, and net ecosystem $\mathrm{CO}_{2}$ exchange(NEE) (d) across all plots in 2015.

along with $\mathrm{N}$ addition rates. Thus, we propose that soil microbial respiration might play a key role in mediating the $\mathrm{N}$ saturation effects for ER and thus NEE, which is not reported in previous studies. The decline in microbial respiration under high $\mathrm{N}$ addition conditions was primarily due to the $\mathrm{N}$ induced reduction in soil $\mathrm{pH}$ (Fig. 7). Although many factors can influence soil microbial respiration, such as soil $\mathrm{N}$ availability and microbial community structure (Janssens et al., 2010), previous studies with a similar $\mathrm{N}$ addition gradient suggested that soil $\mathrm{pH}$ was the most important driver for responses of microbes under high $\mathrm{N}$ addition rates (Liu et al., 2014; Song et al., 2014; Chen et al., 2016). N addition can lead to soil acidification and have negative impacts on soil microbial growth and activities (Liu et al., 2014; Tian et al., 2016). In this study, the decreased soil $\mathrm{pH}$ may cause toxicity effects on microbial activity (Treseder, 2008; Zhou et al., 2012) and thus reduces microbial respiration after 2 years of $\mathrm{N}$ addition.

\subsection{The time and $\mathrm{N}$ threshold for the saturation responses}

Our findings demonstrate that $\mathrm{N}$ responses of ecosystem $\mathrm{C}$ fluxes shifted from a linear response to a saturation response over the 2 years of treatments (Fig. 2). A recent study revealed that ecosystem $\mathrm{C}$ fluxes exhibited saturating responses to $\mathrm{N}$ addition during two consecutive measurement years in a temperate grassland (Tian et al., 2016). However, their measurement was conducted after 10 years of $\mathrm{N}$ addition treatments (similar $\mathrm{N}$ addition rates to our study), so it did not capture the early response signals of ecosystem $\mathrm{C}$ exchange. Results of another $\mathrm{N}$ addition gradient experiment carried out in three marsh ecosystems showed that above-
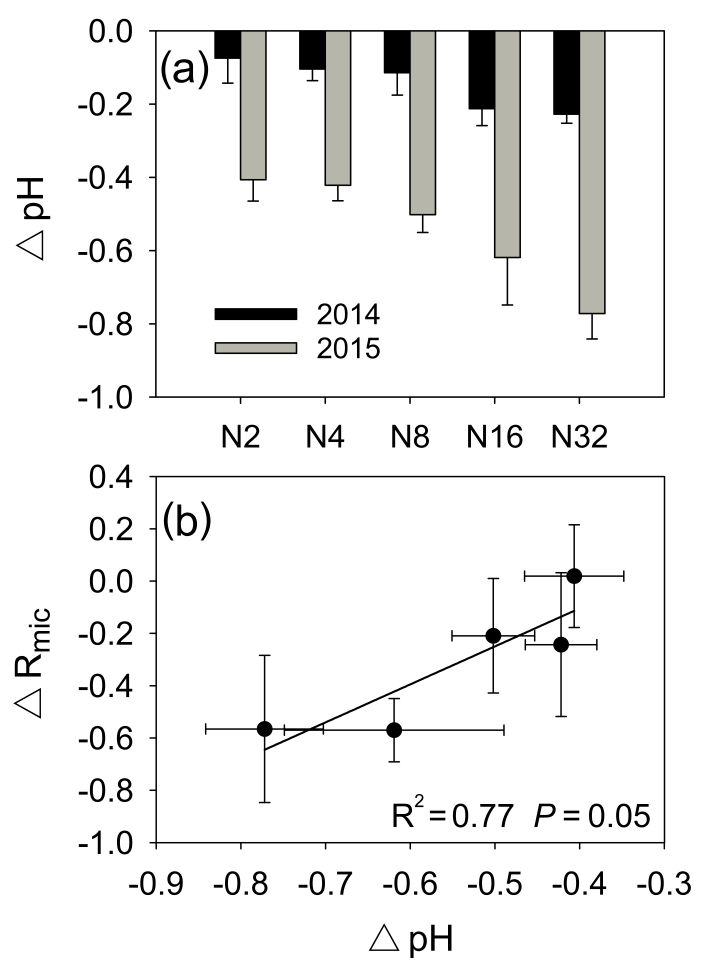

Figure 7. $\mathrm{N}$-induced changes in soil $\mathrm{pH}(\mathrm{pH})$ (a) (mean $\pm \mathrm{SE}$, $n=5$ ) and the dependence of $\mathrm{N}$-induced changes in soil microbial respiration $\left(R_{\text {mic }}\right)$ on $\mathrm{N}$-induced changes in soil $\mathrm{pH}(\mathrm{pH})$ in 2015 (b). N2, N4, N8, N16, and N32 represent N addition rate of 2 , $4,8,16$, and $32 \mathrm{gN} \mathrm{m}^{-2} \mathrm{yr}^{-1}$, respectively.

ground plant biomass increased linearly with $\mathrm{N}$ addition rates after 7 months of treatment but showed saturating responses after 14 months of $\mathrm{N}$ addition (Vivanco et al., 2015). Taken together with our results, this suggests that $\mathrm{N}$ saturation of ecosystem $\mathrm{C}$ fluxes might happen within a couple years of $\mathrm{N}$ input. The different responses between years in this study are not likely due to climate differences because temperature and precipitation were not significantly different between 2014 and 2015. We acknowledge that our findings are only based on the short-term study, while a long-time experiment may capture more robust patterns in $\mathrm{N}$ saturation and the underlying mechanisms, but the findings of the initial shift in $\mathrm{N}$ responses are helpful to better understand the dynamics of the ecosystem in response to external $\mathrm{N}$ input.

The $\mathrm{N}$ saturation threshold for ecosystem $\mathrm{C}$ fluxes of this alpine meadow is approximately $8 \mathrm{gN} \mathrm{m}^{-2} \mathrm{yr}^{-1}$. This level is much higher than that in an alpine steppe on the QinghaiTibetan Plateau (Liu et al., 2013). In Liu et al. (2013), biomass $\mathrm{N}$ concentration, soil $\mathrm{N}_{2} \mathrm{O}$ flux, $\mathrm{N}$-uptake efficiency and $\mathrm{N}$-use efficiency showed saturating responses at an $\mathrm{N}$ addition rate of $4 \mathrm{gN} \mathrm{m}^{-2} \mathrm{yr}^{-1}$. The discrepancy is probably caused by different precipitation at the two sites. The precipitation is $747 \mathrm{~mm}$ at our study site, and it is $415 \mathrm{~mm}$ at their study site. The lower precipitation may constrain the ecosys- 
tem's response to N addition in Liu et al. (2013). Likewise, the $\mathrm{N}$ saturation load in our alpine meadow is higher than that in an alpine dry meadow in Colorado (Bowman et al., 2006) and is comparable with that in a temperate steppe of Eurasian grasslands, which had a saturation $\mathrm{N}$ addition rate of approximately $10.5 \mathrm{gN} \mathrm{m}^{-2} \mathrm{yr}^{-1}$ (Bai et al., 2010). The differences could also relate to the initial nutrient availability at different sites. Ecosystems with high $\mathrm{N}$ availability may reach $\mathrm{N}$ saturation at a low rate of $\mathrm{N}$ addition if there are no other limiting factors. The higher saturation levels indicate that this alpine meadow is more limited by $\mathrm{N}$ compared to other resources. Furthermore, the $\mathrm{N}$ critical load for causing changes in ecosystem $\mathrm{C}$ cycle processes is around $2 \mathrm{gN} \mathrm{m}^{-2} \mathrm{yr}^{-1}$ in this alpine meadow. In the first year, ecosystem $\mathrm{C}$ exchanges were not significantly different between N0 and N2 treatments, but $\mathrm{C}$ fluxes were greater in $\mathrm{N} 2$ plots than in N0 plots in the second year (Fig. 1). This threshold for triggering changes in ecosystem $\mathrm{C}$ fluxes is comparable to that in another alpine meadow on the mid-southern part of the Tibetan Plateau (Zong et al., 2016). Considering that atmospheric wet $\mathrm{N}$ deposition ranges from 0.87 to $1.38 \mathrm{gN} \mathrm{m}^{-2} \mathrm{yr}^{-1}$ on the eastern Qinghai-Tibetan Plateau (Lü and Tian, 2007), our estimate of $\mathrm{N}$ critical load suggests that the ecosystem $\mathrm{C}$ cycle may be largely affected under future $\mathrm{N}$ deposition in the alpine meadow of the Qinghai-Tibetan Plateau.

\subsection{Diverse responses of $\mathrm{C}$ flux components to the $\mathrm{N}$ addition gradient}

The components of ER showed diverse responses to the $\mathrm{N}$ addition gradient (Figs. 4, 5). For example, in 2014, aboveground plant respiration and its proportion to ER increased, but belowground plant respiration and its proportion to ER decreased with $\mathrm{N}$ addition amounts (Figs. 4b, c, 5a, b). To our knowledge, no previous study examined the different components of ER in response to the $\mathrm{N}$ addition gradient. Some studies conducted in alpine grassland demonstrated that $\mathrm{N}$ addition had no significant effects on ER (Jiang et al., 2013; Gong et al., 2014), since aboveground biomass did not respond to $\mathrm{N}$ addition in their studies. In this study, compared to the control treatment (without $\mathrm{N}$ addition), greater plant growth and aboveground biomass under $\mathrm{N}$ addition enhanced aboveground plant respiration and thus stimulated ER. The lack of N effect on SR in 2014 may be attributed to the counteractive responses of soil microbial respiration and root respiration to $\mathrm{N}$ addition. In the first year, $\mathrm{N}$ addition ameliorated the nutrient limitation for microbes; thus, soil microbial activity and biomass increased in the short term (Treseder, 2008) and subsequently stimulated microbial respiration (Peng et al., 2011). On the other hand, N addition could reduce belowground biomass allocation (Haynes and Gower, 1995), leading to a decrease in root respiration. The increase in soil microbial respiration partly offsets the decrease in root respiration. As a result, SR had no significant difference among $\mathrm{N}$ treatments in the first year. How- ever, in the second year, soil microbial respiration declined under high $\mathrm{N}$ addition levels, in combination with the low root respiration, resulting in decreases in SR under N16 and N32 treatments. This decrease in SR was also observed in other ecosystems under long-term or high levels of $\mathrm{N}$ addition (Yan et al., 2010; Zhou and Zhang, 2014; Maaroufi et al., 2015). We are fully aware that there are some limitations for the partitioning technique, in which we used deep versus shallow collars to partition root from microbial respiration. This approach cuts roots and excludes the effects of changes in plant $\mathrm{C}$ allocation on microbial respiration. Soil moisture content may also change in the deep collars, which likely affects microbial respiration. However, this method has the advantage of exploring mechanisms of microbial responses in the absence of plant effects; it is a common and useful technique to partition the components of ER and is widely used in previous studies (Wan et al., 2005; Zhou et al., 2007).

\section{Conclusions}

Based on a field $\mathrm{N}$ addition gradient experiment, this study tested $\mathrm{N}$ saturation theory against multiple $\mathrm{C}$ cycle processes. We found that the ecosystem C fluxes of NEE, GEP, and ER shifted from linear responses to saturation responses over 2 years of $\mathrm{N}$ addition. The saturation responses of NEE and ER were mainly caused by the $\mathrm{N}$-induced saturation response of aboveground plant respiration and decreasing soil microbial respiration along the $\mathrm{N}$ addition gradient. $\mathrm{N}-$ induced reduction in soil $\mathrm{pH}$ was the main mechanism underlying declines in microbial respiration under high $\mathrm{N}$ addition. We also revealed that various components of ER, including aboveground plant respiration, soil respiration, root respiration, and microbial respiration, responded differentially to the $\mathrm{N}$ addition gradient. The findings suggest that the $\mathrm{C}$ cycle processes have differential responses to $\mathrm{N}$ addition between aboveground and belowground plant parts and between plants and microbes. Our findings provide experimental evidence for the dynamic $\mathrm{N}$ responses of the ecosystem $\mathrm{C}$ cycle, which is helpful for parameterizing biogeochemical models and guiding ecosystem management in light of future increasing $\mathrm{N}$ deposition.

Data availability. No data sets were used in this article.

The Supplement related to this article is available online at https://doi.org/10.5194/bg-14-3947-2017-supplement.

Competing interests. The authors declare that they have no conflict of interest. 
Acknowledgements. The authors thank Xiaojing Qin, Yanfang Li, Fangyue Zhang, Quan Quan, Zheng Fu, Qingxiao Yang, and Xiaoqiong Huang for their help in field measurement. We thank the staff of Institute of Qinghai-Tibetan Plateau at Southwest University for Nationalities. This study was financially supported by the National Natural Science Foundation of China (31625006, 31470528), the Ministry of Science and Technology of China (2016YFC0501803, 2013CB956300), the "Thousand Youth Talents Plan", and the West Light Foundation of the Chinese Academy of Sciences.

Edited by: Michael Bahn

Reviewed by: three anonymous referees

\section{References}

Aber, J. D., Nadelhoffer, K. J., Steudler, P., and Melillo, J. M.: Nitrogen saturation in northern forest ecosystems, Bioscience, 39, 378-286, 1989.

Aber, J. D., McDowell, W., Nadelhoffer, K., Magill, A., Berntson, G., Kamakea, M., McNulty, S., Currie, W., Rustad, L., and Fernandez, I.: Nitrogen saturation in temperate forest ecosystems - Hypotheses revisited, Bioscience, 48, 921-934, https://doi.org/10.2307/1313296, 1998.

Bai, Y., Wu, J., Clark, C. M., Naeem, S., Pan, Q., Huang, J., Zhang, L., and Han, X.: Tradeoffs and thresholds in the effects of nitrogen addition on biodiversity and ecosystem functioning: evidence from Inner Mongolia Grasslands, Glob. Change Biol., 16, 358-372, https://doi.org/10.1111/j.1365-2486.2009.01950.x, 2010.

Bowman, W. D., Gartner, J. R., Holland, K., and Wiedermann, M.: Nitrogen critical loads for alpine vegetation and terrestrial ecosystem response: Are we there yet?, Ecol. Appl., 16, 11831193, 2006.

Bubier, J. L., Moore, T. R., and Bledzki, L. A.: Effects of nutrient addition on vegetation and carbon cycling in an ombrotrophic bog, Glob. Change Biol., 13, 1168-1186, https://doi.org/10.1111/j.1365-2486.2007.01346.x, 2007.

Chen, D., Li, J., Lan, Z., Hu, S., and Bai, Y.: Soil acidification exerts a greater control on soil respiration than soil nitrogen availability in grasslands subjected to long-term nitrogen enrichment, Funct. Ecol., 30, 658-669, 2016.

Chen, H., Zhu, Q., Peng, C., Wu, N., Wang, Y., Fang, X., Gao, Y., Zhu, D., Yang, G., and Tian, J.: The impacts of climate change and human activities on biogeochemical cycles on the QinghaiTibetan Plateau, Glob. Change Biol., 19, 2940-2955, 2013.

Fernandez-Martinez, M., Vicca, S., Janssens, I. A., Sardans, J., Luyssaert, S., Campioli, M., Chapin, F. S., Ciais, P., Malhi, Y., Obersteiner, M., Papale, D., Piao, S. L., Reichstein, M., Roda, F., and Penuelas, J.: Nutrient availability as the key regulator of global forest carbon balance, Nature Climate Change, 4, 471476, https://doi.org/10.1038/Nclimate2177, 2014.

Fleischer, K., Rebel, K. T., van der Molen, M. K., Erisman, J. W., Wassen, M. J., van Loon, E. E., Montagnani, L., Gough, C. M., Herbst, M., Janssens, I. A., Gianelle, D., and Dolman, A. J.: The contribution of nitrogen deposition to the photosynthetic capacity of forests, Global Biogeochem. Cy., 27, 187-199, https://doi.org/10.1002/gbc.20026, 2013.
Galloway, J. N., Townsend, A. R., Erisman, J. W., Bekunda, M., Cai, Z. C., Freney, J. R., Martinelli, L. A., Seitzinger, S. P., and Sutton, M. A.: Transformation of the nitrogen cycle: Recent trends, questions, and potential solutions, Science, 320, 889-892, https://doi.org/10.1126/science.1136674, 2008.

Gomez-Casanovas, N., Hudiburg, T. W., Bernacchi, C. J., Parton, W. J., and Delucia, E. H.: Nitrogen deposition and greenhouse gas emissions from grasslands: Uncertainties and future directions, Glob. Change Biol., 22, 1348-1360, https://doi.org/10.1111/gcb.13187, 2016.

Gong, Y. M., Mohammat, A., Liu, X. J., Li, K. H., Christie, P., Fang, F., Song, W., Chang, Y. H., Han, W. X., Lü, X. T., Liu, Y. Y., and Hu, Y. K.: Response of carbon dioxide emissions to sheep grazing and $\mathrm{N}$ application in an alpine grassland Part 1: Effect of sheep grazing, Biogeosciences, 11, 1743-1750, https://doi.org/10.5194/bg-11-1743-2014, 2014.

Harpole, W. S., Potts, D. L., and Suding, K. N.: Ecosystem responses to water and nitrogen amendment in a California grassland, Glob. Change Biol., 13, 2341-2348, https://doi.org/10.1111/j.1365-2486.2007.01447.x, 2007.

Hasselquist, N. J., Metcalfe, D. B., and Högberg, P.: Contrasting effects of low and high nitrogen additions on soil $\mathrm{CO}_{2}$ flux components and ectomycorrhizal fungal sporocarp production in a boreal forest, Glob. Change Biol., 18, 3596-3605, 2012.

Haynes, B. E. and Gower, S. T.: Belowground carbon allocation in unfertilized and fertilized red pine plantations in northern Wisconsin, Tree Physiol., 15, 317-325, 1995.

Huff, L. M., Potts, D. L., and Hamerlynck, E. P.: Ecosystem $\mathrm{CO}_{2}$ exchange in response to nitrogen and phosphorus addition in a restored, temperate Grassland, The Am. Midl. Nat., 173, 73-87, 2015.

Janssens, I., Dieleman, W., Luyssaert, S., Subke, J.-A., Reichstein, M., Ceulemans, R., Ciais, P., Dolman, A. J., Grace, J., and Matteucci, G.: Reduction of forest soil respiration in response to nitrogen deposition, Nat. Geosci., 3, 315-322, 2010.

Jiang, J., Zong, N., Song, M., Shi, P., Ma, W., Fu, G., Shen, Z., Zhang, X., and Ouyang, H.: Responses of ecosystem respiration and its components to fertilization in an alpine meadow on the Tibetan Plateau, Eur. J. Soil Biol., 56, 101-106, 2013.

Kim, M. K. and Henry, H. A.: Net ecosystem $\mathrm{CO}_{2}$ exchange and plant biomass responses to warming and $\mathrm{N}$ addition in a grassdominated system during two years of net $\mathrm{CO}_{2}$ efflux, Plant Soil, 371, 409-421, 2013.

Lamarque, J. F., Kiehl, J. T., Brasseur, G. P., Butler, T., CameronSmith, P., Collins, W. D., Collins, W. J., Granier, C., Hauglustaine, D., Hess, P. G., Holland, E. A., Horowitz, L., Lawrence, M. G., McKenna, D., Merilees, P., Prather, M. J., Rasch, P. J., Rotman, D., Shindell, D., and Thornton, P.: Assessing future nitrogen deposition and carbon cycle feedback using a multimodel approach: Analysis of nitrogen deposition, J. Geophys. Res.Atmos., 110, D19303, https://doi.org/10.1029/2005jd005825, 2005.

LeBauer, D. S. and Treseder, K. K.: Nitrogen limitation of net primary productivity in terrestrial ecosystems is globally distributed, Ecology, 89, 371-379, https://doi.org/10.1890/062057.1, 2008.

Liu, L. L. and Greaver, T. L.: A global perspective on belowground carbon dynamics under nitrogen enrichment, Ecol. Lett., 
13, 819-828, https://doi.org/10.1111/j.1461-0248.2010.01482.x, 2010.

Liu, W., Jiang, L., Hu, S., Li, L., Liu, L., and Wan, S.: Decoupling of soil microbes and plants with increasing anthropogenic nitrogen inputs in a temperate steppe, Soil Biol. Biochem., 72, 116-122, 2014.

Liu, Y. W., Xu, X. L., Wei, D., Wang, Y. H., and Wang, Y. S.: Plant and soil responses of an alpine steppe on the Tibetan Plateau to multi-level nitrogen addition, Plant Soil, 373, 515-529, 2013.

Lovett, G. M. and Goodale, C. L.: A new conceptual model of nitrogen saturation based on experimental nitrogen addition to an oak forest, Ecosystems, 14, 615-631, https://doi.org/10.1007/s10021-011-9432-z, 2011.

Lu, M., Zhou, X. H., Luo, Y. Q., Yang, Y. H., Fang, C. M., Chen, J. K., and Li, B.: Minor stimulation of soil carbon storage by nitrogen addition: A meta-analysis, Agr. Ecosyst. Environ., 140, 234-244, https://doi.org/10.1016/j.agee.2010.12.010, 2011.

Lü, C. Q. and Tian, H. Q.: Spatial and temporal patterns of nitrogen deposition in China: synthesis of observational data, J. Geophys. Res.-Atmos., 112, D22S05, https://doi.org/10.1029/2004GB002315, 2007.

Maaroufi, N. I., Nordin, A., Hasselquist, N. J., Bach, L. H., Palmqvist, K., and Gundale, M. J.: Anthropogenic nitrogen deposition enhances carbon sequestration in boreal soils, Glob. Change Biol., 21, 3169-3180, 2015.

Magnani, F., Mencuccini, M., Borghetti, M., Berbigier, P., Berninger, F., Delzon, S., Grelle, A., Hari, P., Jarvis, P. G., and Kolari, P.: The human footprint in the carbon cycle of temperate and boreal forests, Nature, 447, 849-851, 2007.

Nadelhoffer, K. J., Emmett, B. A., Gundersen, P., Kjonaas, O. J., Koopmans, C. J., Schleppi, P., Tietema, A., and Wright, R. F.: Nitrogen deposition makes a minor contribution to carbon sequestration in temperate forests, Nature, 398, 145-148, https://doi.org/10.1038/18205, 1999.

Niu, S., Wu, M., Han, Y., Xia, J., Li, L., and Wan, S.: Watermediated responses of ecosystem carbon fluxes to climatic change in a temperate steppe, New Phytol., 177, 209-219, 2008.

Niu, S., Sherry, R. A., Zhou, X., and Luo, Y.: Ecosystem carbon fluxes in response to warming and clipping in a tallgrass prairie, Ecosystems, 16, 948-961, 2013.

Niu, S. L., Wu, M. Y., Han, Y., Xia, J. Y., Zhang, Z., Yang, H. J., and Wan, S. Q.: Nitrogen effects on net ecosystem carbon exchange in a temperate steppe, Glob. Change Biol., 16, 144-155, https://doi.org/10.1111/j.1365-2486.2009.01894.x, 2010.

Peng, Q., Dong, Y., Qi, Y., Xiao, S., He, Y., and Ma, T.: Effects of nitrogen fertilization on soil respiration in temperate grassland in Inner Mongolia, China, Environ. Earth Sci., 62, 1163-1171, 2011.

Phillips, R. P. and Fahey, T. J.: Fertilization effects on fineroot biomass, rhizosphere microbes and respiratory fluxes in hardwood forest soils, New Phytol., 176, 655-664, 2007.

Reay, D. S., Dentener, F., Smith, P., Grace, J., and Feely, R. A.: Global nitrogen deposition and carbon sinks, Nat. Geosci., 1, 430-437, 2008.
Song, B., Niu, S. L., Li, L. H., Zhang, L. X., and Yu, G. R.: Soil carbon fractions in grasslands respond differently to various levels of nitrogen enrichments, Plant Soil, 384, 401-412, 2014.

Tian, D. S., Niu, S. L., Pan, Q. M., Ren, T. T., Chen, S. Q., Bai, Y. F., and Han, X. G.: Nonlinear responses of ecosystem carbon fluxes and water-use efficiency to nitrogen addition in Inner Mongolia grassland, Funct. Ecol., 30, 490-499, https://doi.org/10.1111/1365-2435.12513, 2016.

Treseder, K. K.: Nitrogen additions and microbial biomass: A meta-analysis of ecosystem studies, Ecol. Lett., 11, 1111-1120, https://doi.org/10.1111/j.1461-0248.2008.01230.x, 2008.

Vivanco, L., Irvine, I. C., and Martiny, J. B. H.: Nonlinear responses in salt marsh functioning to increased nitrogen addition, Ecology, 96, 936-947, https://doi.org/10.1890/13-1983.1, 2015.

Wan, S., Hui, D., Wallace, L., and Luo, Y.: Direct and indirect effects of experimental warming on ecosystem carbon processes in a tallgrass prairie, Global Biogeochem. Cy., 19, GB2014, https://doi.org/10.1029/2006JD007990, 2005.

Xia, J. Y. and Wan, S. Q.: Global response patterns of terrestrial plant species to nitrogen addition, New Phytol., 179, 428-439, https://doi.org/10.1111/j.1469-8137.2008.02488.x, 2008.

Yan, L., Chen, S., Huang, J., and Lin, G.: Differential responses of auto- and heterotrophic soil respiration to water and nitrogen addition in a semiarid temperate steppe, Glob. Change Biol., 16, 2345-2357, 2010.

Zhou, L. Y., Zhou, X. H., Zhang, B. C., Lu, M., Luo, Y. Q., Liu, L. L., and Li, B.: Different responses of soil respiration and its components to nitrogen addition among biomes: A meta-analysis, Glob. Change Biol., 20, 2332-2343, https://doi.org/10.1111/Gcb.12490, 2014.

Zhou, X. and Zhang, Y.: Seasonal pattern of soil respiration and gradual changing effects of nitrogen addition in a soil of the Gurbantunggut Desert, northwestern China, Atmos. Environ., 85, 187-194, 2014.

Zhou, X., Wan, S., and Luo, Y.: Source components and interannual variability of soil $\mathrm{CO}_{2}$ efflux under experimental warming and clipping in a grassland ecosystem, Glob. Change Biol., 13, 761775, 2007.

Zhou, X., Zhang, Y., and Downing, A.: Non-linear response of microbial activity across a gradient of nitrogen addition to a soil from the Gurbantunggut Desert, northwestern China, Soil Biol. Biochem., 47, 67-77, 2012.

Zhu, C., Ma, Y. P., Wu, H. H., Sun, T., La Pierre, K. J., Sun, Z. W., and Yu, Q.: Divergent Effects of nitrogen addition on soil respiration in a semiarid grassland, Sci. Rep., 6, 33541, https://doi.org/10.1038/srep33541, 2016.

Zong, N., Shi, P., Song, M., Zhang, X., Jiang, J., and Chai, X.: Nitrogen critical loads for an alpine meadow ecosystem on the Tibetan Plateau, Environ. Manage., 57, 531-542, https://doi.org/10.1007/s00267-015-0626-6, 2016. 